Supplementary Information for:

\title{
A four-step pathway from phenylpyruvate to benzylamine, an intermediate to the high-energy propellant CL-20
}

Ramesh Prasad Pandey ${ }^{1,2}$, Arturo Casini ${ }^{2}$, Christopher A. Voigt ${ }^{1,2}$, and D. Benjamin Gordon ${ }^{1,2 *}$

${ }^{1}$ Synthetic Biology Center, Department of Biological Engineering,

Massachusetts Institute of Technology, Cambridge, MA, 02139, USA

${ }^{2}$ The Broad Institute of MIT and Harvard, Cambridge, MA 02142, USA

Corresponding author:

D. Benjamin Gordon

Email: ben@synbiofoundry.org

\section{Contents}

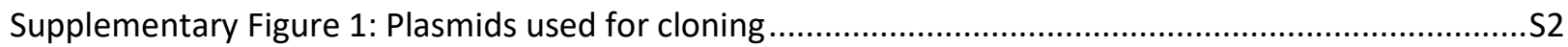

Supplementary Figure 2: Plasmids assembled for this study ............................................................ 3

Supplementary Figure 3: Standard curves for benzylamine, (S)-mandelic acid, and phenylalanine ........S6

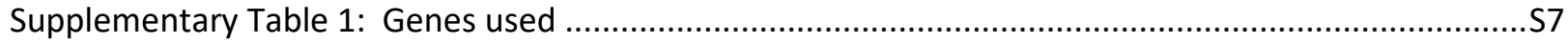

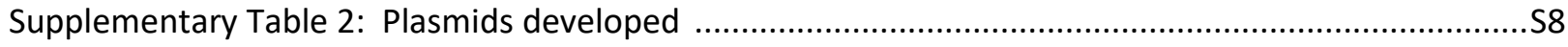

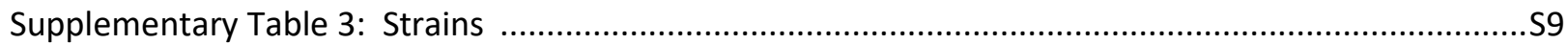

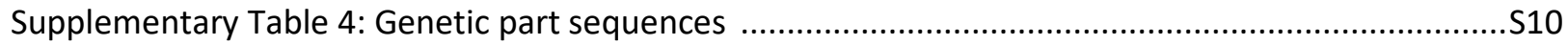

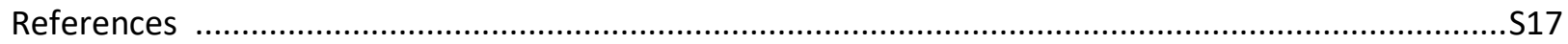




\section{Supplementary Figure 1}

A

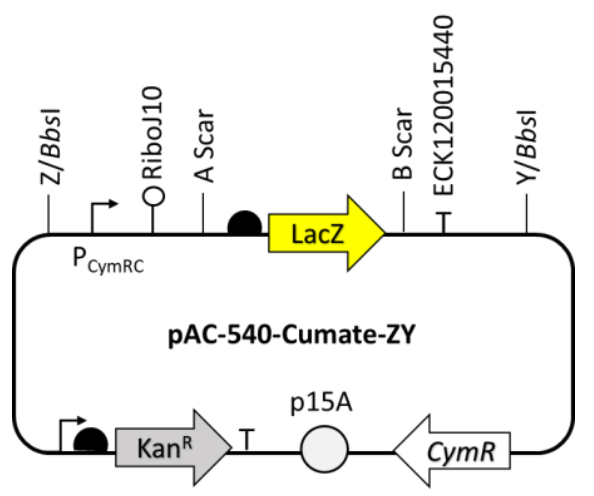

C

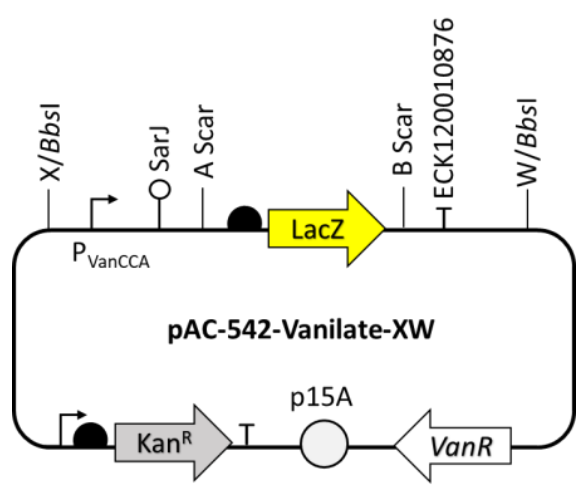

B

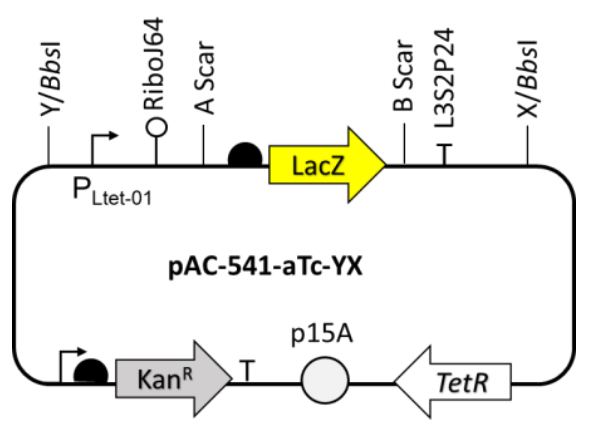

D

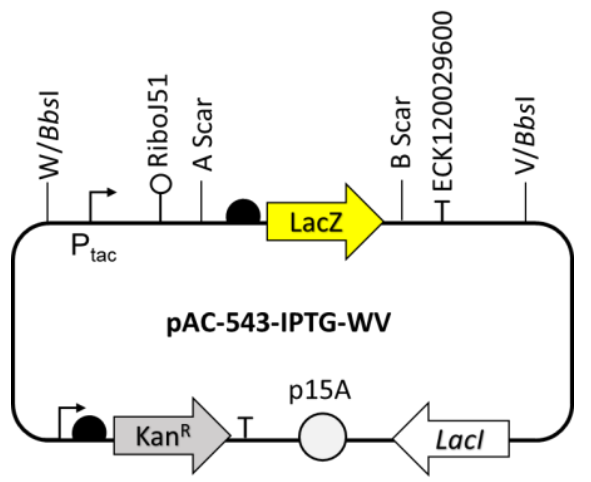

E

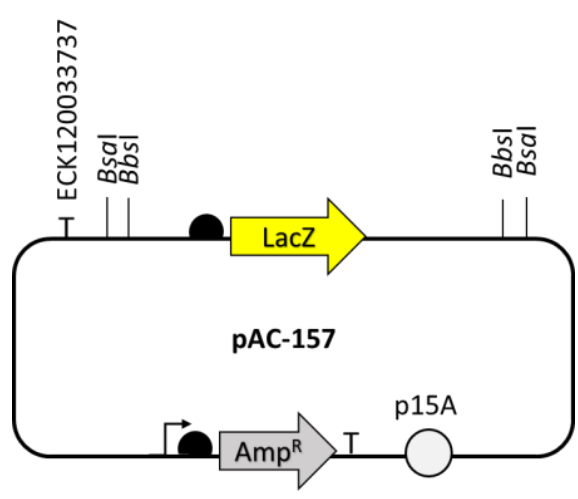

Plasmids used to construct functional biosynthesis pathway of benzylamine. (A-D) Level I plasmids used to clone genes under different promoters. For example, all three HmaS genes were cloned in pAC.540Cumate, $s c H m O$ and $p p M d I C$ were cloned in pAc.541-aTc and pAC.542-vanilate, respectively. All five amine transaminases encoding genes were cloned in PAC.543-IPTG. (E) Plasmids used to assemble different pathway genes cloned under different promoters in level I plasmids using $B b s$ l enzyme. 
Supplementary Figure 2
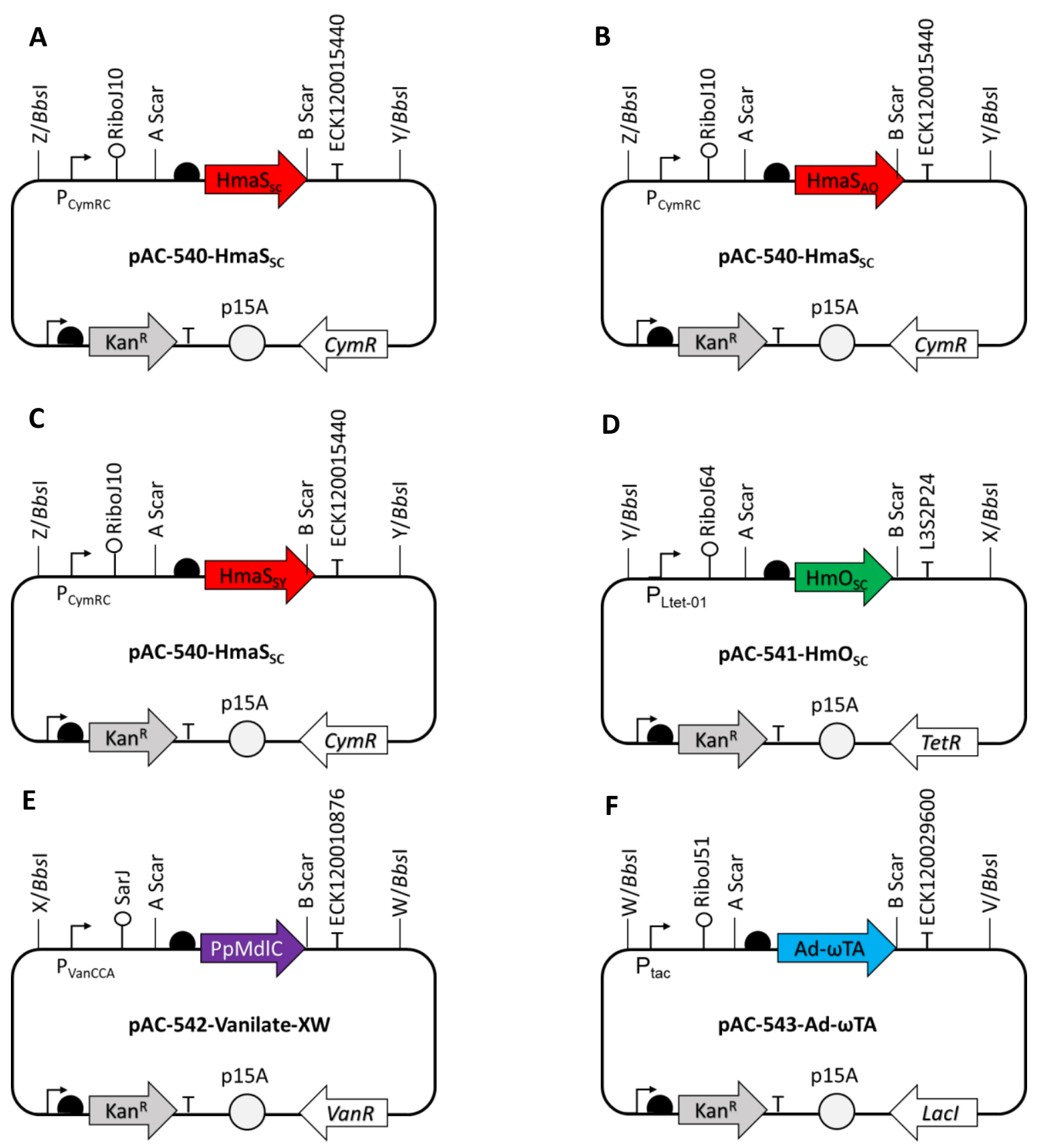

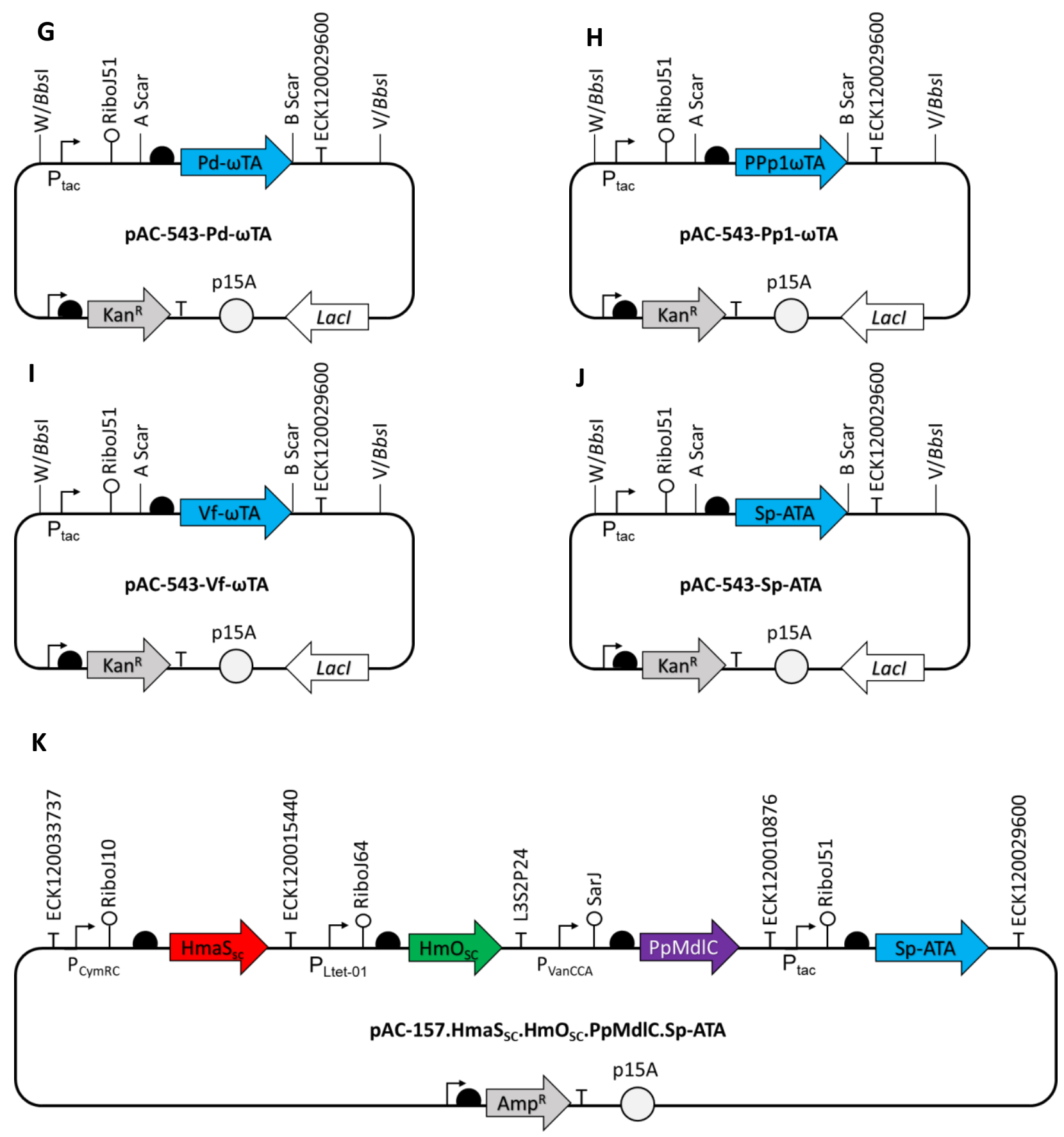


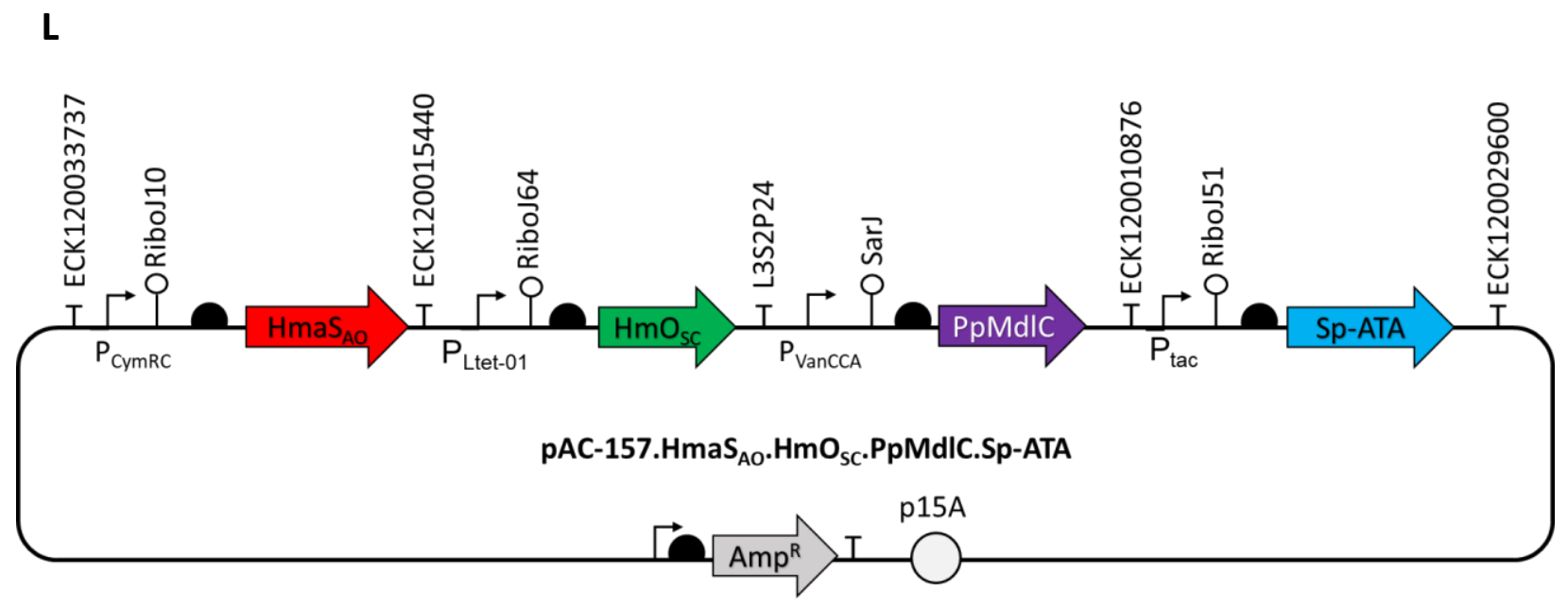

Recombinant plasmids developed during this study. (A-C) Mandelate synthases cloned under cumate inducible promoter in pAC.540-Cumate plasmid. (D) Mandelate oxidase gene cloned under aTc inducible promoter in a pAC.541.aTc plasmid. (E) Benzoylformate decarboxylase gene cloned under vanilate inducible promoter in a pAC.542-vanilate plasmid. (F-J) Amine transaminase genes cloned under IPTG inducible promoter in a pAC.543-IPTG plasmid. (K) Plasmid for benzylamine biosynthesis in E. coli starting from phenylpyruvate-the mandelate synthase and mandelate oxidase genes are from $S$. coelicolor, benzoylformate decarboxylase is from $P$. putida, and amine transaminase is from S. pomeroyi. (L) Plasmid for benzylamine biosynthesis in E. coli starting from phenylpyruvate-the mandelate synthase genes is from $A$. orientalis and mandelate oxidase genes are from $S$. coelicolor, benzoylformate decarboxylase is from $P$. putida, and amine transaminase is from S. pomeroyi. All four genes are assembled under different promoters. The sequences of all different parts, genes, and full plasmid are provided in Supplementary Table 4. 


\section{Supplementary Figure 3}

A

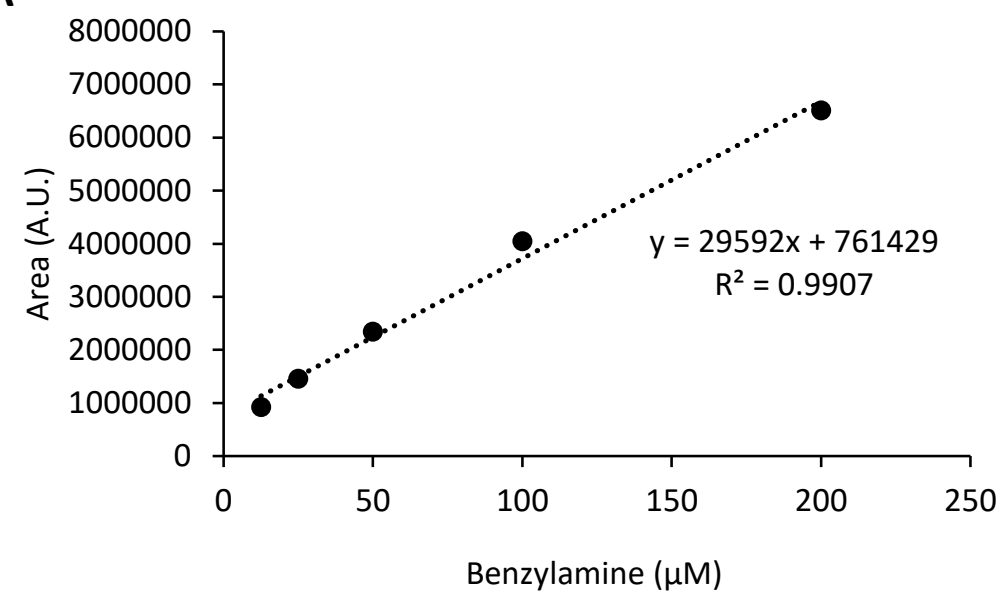

B

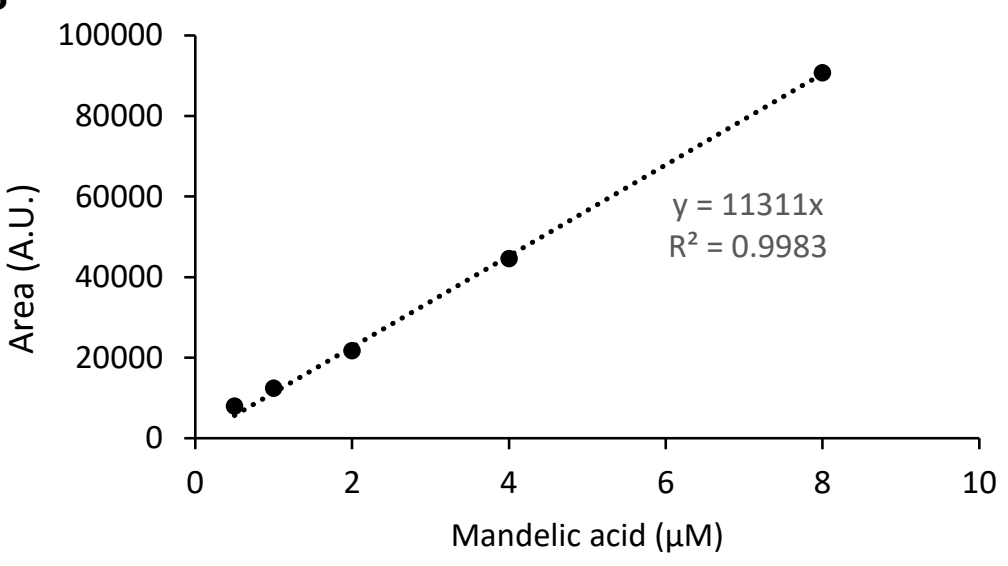

C

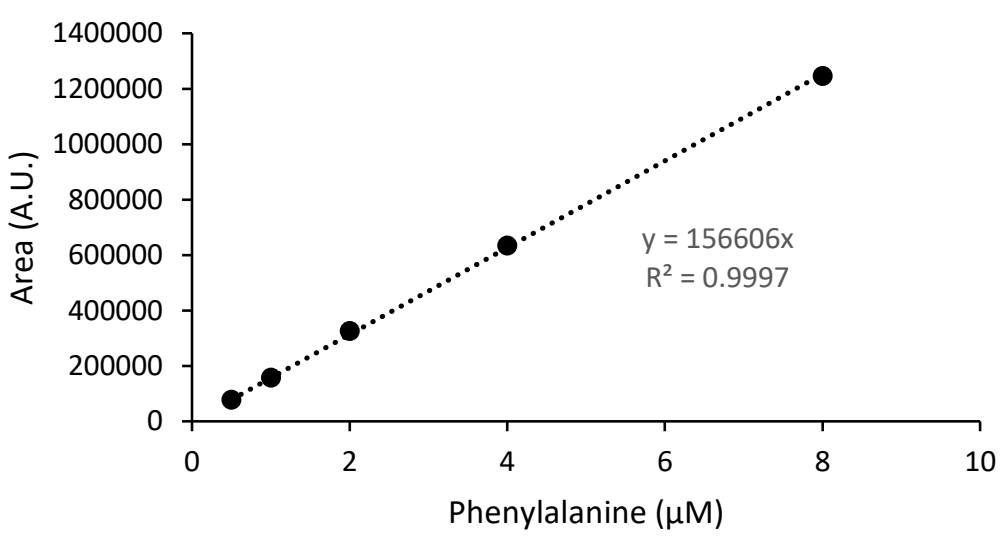

Standard LC/MS curves of (A) benzylamine, (B) (S)-mandelic acid, and (C) phenylalanine are shown. A single replicate was measured for each datapoint. 
Supplementary Table 1. Source and accession no of genes used in this study

\begin{tabular}{|c|c|c|c|}
\hline Name & Function & Source & Accession No \\
\hline $\mathrm{ScHmaS}$ & \multirow{21}{*}{ Mandelate Synthase } & Streptomyces coelicolor A3(2) & CAB38519.1 \\
\hline AoHmaS & & Amycolatopsis orientalis ATCC19795 & HE589771.1 \\
\hline SyHmaS & & $\begin{array}{l}\text { Streptomyces yokosukanensis } \\
\text { strain DSM } 40224\end{array}$ & KUN01456.1 \\
\hline KsRHmaS & & Kitasatospora sp. Root107 & WP_082598593.1 \\
\hline SsSHmaS & & Streptomyces sp. SID14446 & WP_164370403.1 \\
\hline ThHmaS & & $\begin{array}{l}\text { Thermobifida halotolerans strain DSM } \\
44931\end{array}$ & WP_068690623.1 \\
\hline SIHmaS & & Streptomyces lydicus & WP_069571457.1 \\
\hline KsNHmaS & & Kitasatospora sp. NRRL B-11411 & WP_035954346.1 \\
\hline LaHmaS & & Lentzea albida & WP_089909334.1 \\
\hline mGeHmaS & & uncultured bacterium esnapd15 & AGS49757.1 \\
\hline SsRHmaS & & Streptomyces sp. RP5T & WP_125191956.1 \\
\hline Ss1HmaS & & Streptomyces sp. 1114.5 & WP_121175987.1 \\
\hline NsHmaS & & Nocardiopsis sp. L17-MgMaSL7 & WP_110049691.1 \\
\hline Ss $2 \mathrm{HmaS}$ & & Streptomyces sp. 2132.2 & ROR00226.1 \\
\hline $\mathrm{SsCHmaS}$ & & Streptomyces sp. CB02923 & WP_073763497.1 \\
\hline SaHmaS & & Streptomyces avermitilis & WP_037648216.1 \\
\hline SsYHmaS & & Streptomyces sp. YIM 121038 & WP_138967404.1 \\
\hline KaHmaS & & Kibdelosporangium aridum & WP_084433281.1 \\
\hline VEGHmaS & & VEG30 uncultured soil bacterium & ACJ60972.1 \\
\hline AsHmaS & & Amycolatopsis sp. BJA-103 & WP_101612851.1 \\
\hline AtHmaS & & Actionoplanes teichomyceticus & CAG15040 \\
\hline $\mathrm{ScHmO}$ & Mandelate oxidase & Streptomyces coelicolor A3(2) & AL939115.1 \\
\hline PpMdlC & $\begin{array}{l}\text { Benzoylformate } \\
\text { decarboxylase }\end{array}$ & Pseudomonas putida 12633 & AAC15502.1 \\
\hline AD $\omega T A$ & \multirow{5}{*}{ Aminotransferase } & Alcaligenes denitrificans Y2k-2 & AAP92672.1 \\
\hline Pp1wTA & & Pseudomonas putida KT2440 & AAN70747.1 \\
\hline Pd $\omega T A$ & & Paracoccus denitrificans & ABL72050.1 \\
\hline VfwTA & & Vibrio fluvialis & AEA39183.1 \\
\hline SpATA & & Salicibacter pomeroyi DSS-3 & AAV96697.1 \\
\hline
\end{tabular}


Supplementary Table 2. List of the plasmids developed in this study

\begin{tabular}{|c|c|}
\hline Plasmids & Details \\
\hline \multicolumn{2}{|l|}{ pET Expression Plasmids } \\
\hline pET24a(+)-AdwTA & AdwTA cloned in Sacl and HindllI sites of pET24a(+) \\
\hline pET24a(+)-PdwTA & PdwTA cloned in Sacl and HindIII sites of pET24a(+) \\
\hline pET24a(+)-Pp1wTA & Pp1wTA cloned in Sacl and HindIII sites of pET24a(+) \\
\hline pET24a(+)-VfwTA & Vf $\omega T$ A cloned in Sacl and HindlII sites of pET24a(+) \\
\hline pET24a(+)-SpATA & SpATA cloned in Sacl and HindIII sites of pET24a(+) \\
\hline \multicolumn{2}{|l|}{ Level I Plasmids } \\
\hline pAC.540-Cumate-ZY & $\begin{array}{l}\text { Cumate inducble promoter PCymRC with ZY scars (Z: ATAG, Y: } \\
\text { CACA) }\end{array}$ \\
\hline pAC.541-aTc-YX & $\begin{array}{l}\text { Anhydro tetracycline inducible PLtet- } 01 \text { promoter with } \mathrm{YX} \text { scars (Y: } \\
\text { CACA, X: CTCG) }\end{array}$ \\
\hline pAC.542-Van-XW & $\begin{array}{l}\text { Vanilate inducble promoter PVanCCA with XW scars (X: CTCG, W: } \\
\text { TTAC) }\end{array}$ \\
\hline pAC.543-IPTG-WV & IPTG inducble promoter Ptac with XW scars (W: TTAC, V: ATTC) \\
\hline pAC.540-ScHmaS & ScHmaS gene under cumate inducible $\mathrm{P}_{\mathrm{cymRc}}$ promoter \\
\hline pAC.540-AoHmaS & AoHmaS gene under cumate inducible $\mathrm{P}_{\text {cymRc }}$ promoter \\
\hline pAC.540-SyHmaS & SyHmaS gene under cumate inducible $\mathrm{P}_{\text {cymRc }}$ promoter \\
\hline pAC.541-ScHmO & ScHmO gene under aTc inducible $P_{\text {Ltet-01 }}$ promoter \\
\hline pAC.542-PpMdIC & PpMdIC gene under vanilate inducible $\mathrm{P}_{\text {vancca }}$ promoter \\
\hline pAC.543-AdwTA & AdwTA gene under IPTG inducible $P_{\text {tac }}$ promoter \\
\hline 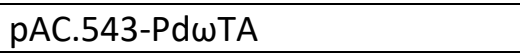 & PdwTA gene under IPTG inducible $\mathrm{P}_{\text {tac }}$ promoter \\
\hline 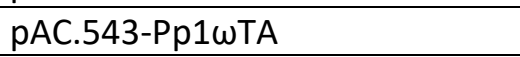 & Pp1wTA gene under IPTG inducible $P_{\text {tac }}$ promoter \\
\hline pAC.543-Vf $\omega T A$ & Vf $\omega$ TA gene under IPTG inducible $P_{\text {tac }}$ promoter \\
\hline pAC.543-SpwTA & SpATA gene under IPTG inducible $P_{\text {tac }}$ promoter \\
\hline \multicolumn{2}{|l|}{ Level II Plasmids } \\
\hline $\begin{array}{l}\text { pAC-157- } \\
\text { ScHmaS.ScHmO.PpMdIC.SpATA }\end{array}$ & $\begin{array}{l}\text { pAC-157 plasmid with assembled biosynthetic pathway } \\
\text { transcription units } \mathrm{ScHmaS}, \mathrm{ScHmO} \text {, PpMdIC, and SpATA under } \\
\mathrm{P}_{\text {CymRC }}, \mathrm{P}_{\text {Ltet-01, }}, \mathrm{P}_{\text {VancCA, }} \text { and } \mathrm{P}_{\text {tac }} \text { promoter, respectively }\end{array}$ \\
\hline $\begin{array}{l}\text { pAC-157- } \\
\text { AoHmaS.ScHmO.PpMdIC.SpATA }\end{array}$ & $\begin{array}{l}\text { pAC-157 plasmid with assembled biosynthetic pathway } \\
\text { transcription units } A \text { oHmaS, ScHmO, PpMdIC, and SpATA under } \\
\mathrm{P}_{\text {CymRC, }} \mathrm{P}_{\text {Ltet }-01,} \mathrm{P}_{\text {VancCA, }} \text { and } \mathrm{P}_{\text {tac }} \text { promoter, respectively }\end{array}$ \\
\hline
\end{tabular}


Supplementary Table 3. Recombinant strains developed for benzylamine production

\begin{tabular}{|c|c|c|}
\hline Strains & Details & Source/References \\
\hline $\begin{array}{l}\text { E. coli } \mathrm{NEB}^{\circledR} 10- \\
\text { beta }\end{array}$ & $\begin{array}{l}\Delta \text { (ara-leu) } 7697 \text { araD139 fhuA } \Delta \text { lacX74 galK16 galE15 } \\
\text { e14- } \phi 80 d l a c Z \Delta M 15 \text { recA1 relA1 endA1 nupG rpsL (StrR) } \\
\text { rph spoT1 } \Delta \text { (mrr-hsdRMS-mcrBC) }\end{array}$ & $\begin{array}{l}\text { New England } \\
\text { BioLabs Inc. }\end{array}$ \\
\hline $\begin{array}{l}\text { E. coli T7 Express } \\
\text { lysY/lq }\end{array}$ & $\begin{array}{l}\text { MiniF lysY laclq(Cam }{ }^{\mathrm{R}} \text { ) / fhuA2 lacZ::T7 gene1 [lon] ompT } \\
\text { gal sulA11 R(mcr-73::miniTn10--TetS)2 [dcm] R(zgb- } \\
\text { 210::Tn10--TetS) endA1 } \Delta \text { (mcrC-mrr) 114::IS10 }\end{array}$ & $\begin{array}{l}\text { New England } \\
\text { BioLabs Inc. }\end{array}$ \\
\hline $\begin{array}{l}\text { E. coli Marionette } \\
\text { Pro }\end{array}$ & $\begin{array}{l}\text { E. coli BL21(DE3) strain modified for sensing } 12 \text { different } \\
\text { inducer molecules for expression of proteins }\end{array}$ & Ref. 1 \\
\hline \multicolumn{3}{|c|}{ Strains transforming benzaldehyde to benzylamine } \\
\hline 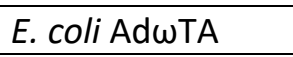 & E. coli Express $/ y s Y / I^{a}$ harboring pET24a(+)-Ad $\omega T A$ plasmid & This study \\
\hline E. coli PdwTA & E. coli Express $/ y s Y / I^{a}$ harboring pET24a(+)-PdwTA plasmid & This study \\
\hline E. coli Pp1wTA & $\begin{array}{l}\text { E. coli Express } l y s Y / I^{q} \text { harboring pET24a(+)-Pp1 } 1 \omega \mathrm{TA} \\
\text { plasmid }\end{array}$ & This study \\
\hline E. coli Vf $\omega \mathrm{TA}$ & E. coli Express $/ y s Y / I^{a}$ harboring pET24a(+)-Vf $\omega T$ TA plasmid & This study \\
\hline E. coli SpATA & E. coli Express lys $Y / I^{q}$ harboring pET24a(+)-SpATA plasmid & This study \\
\hline \multicolumn{3}{|c|}{ Strains producing benzylamine from phenylpyruvate } \\
\hline $\begin{array}{l}\text { E. coli Marionette } \\
\text { Pro ScSOCSpAT }\end{array}$ & $\begin{array}{l}\text { E. coli Marionette Pro harboring } \\
\text { pAC.157-ScHmaS.ScHmO.PpMdIC.SpATA plasmid }\end{array}$ & This study \\
\hline $\begin{array}{l}\text { E. coli Marionette } \\
\text { Pro AoSOCSpAT }\end{array}$ & $\begin{array}{l}\text { E. coli Marionette Pro harboring } \\
\text { pAC.157-AoHmaS.ScHmO.PpMdIC.SpATA plasmid }\end{array}$ & This study \\
\hline
\end{tabular}


Supplementary Table 4: Genetic part sequences

\begin{tabular}{|c|c|c|}
\hline Part Name & Part Type & Sequence \\
\hline $\mathrm{P}_{\text {CymRC }}$ & Promoter & aacaaacagacaatctggtctgtttgtattatggaaaatttttctgtataatagattcaacaaacagacaatctggtctgtttgtattat \\
\hline RiboJ10 & Insulator & agcgctcaacgggtgtgcttcccgttctgatgagtccgtgaggacgaaagcgcctctacaaataattttgtttaa \\
\hline RBS-ScHmaS & RBS & tccatatttaaggaggtctattt \\
\hline ScHmaS & Gene & 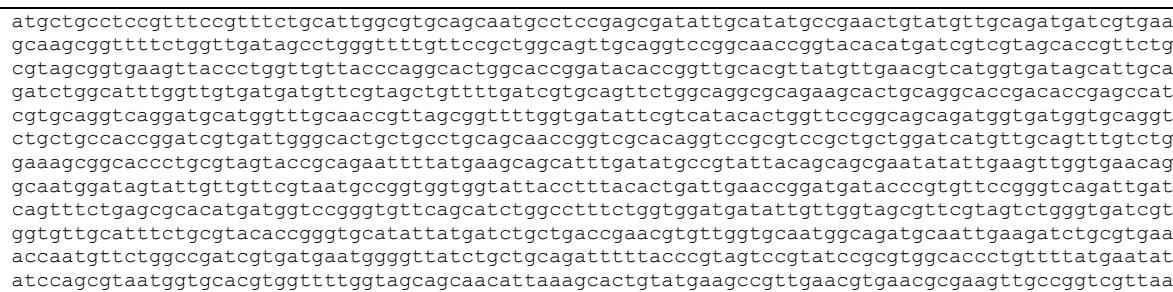 \\
\hline RBS-AoHmaS & RBS & cgatagttagacgctaaggaggtttttg \\
\hline AoHmaS & Gene & 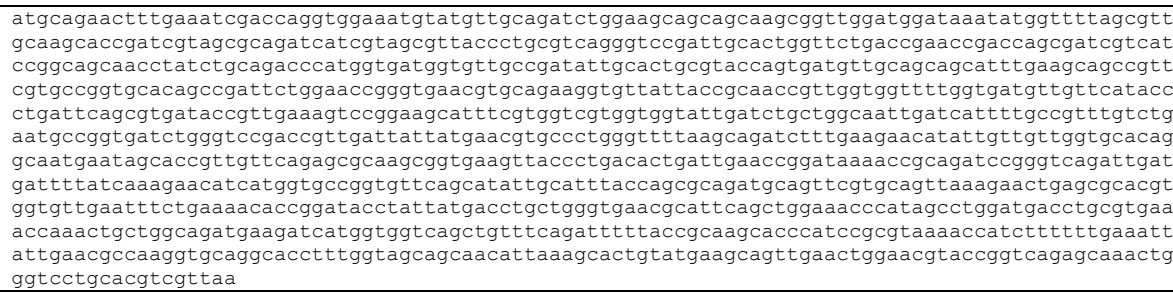 \\
\hline RBS-SyHmaS & RBS & cccgttgggcgatttaaaaagcataagtaataataaggaggttttttt \\
\hline SyHmaS & Gene & 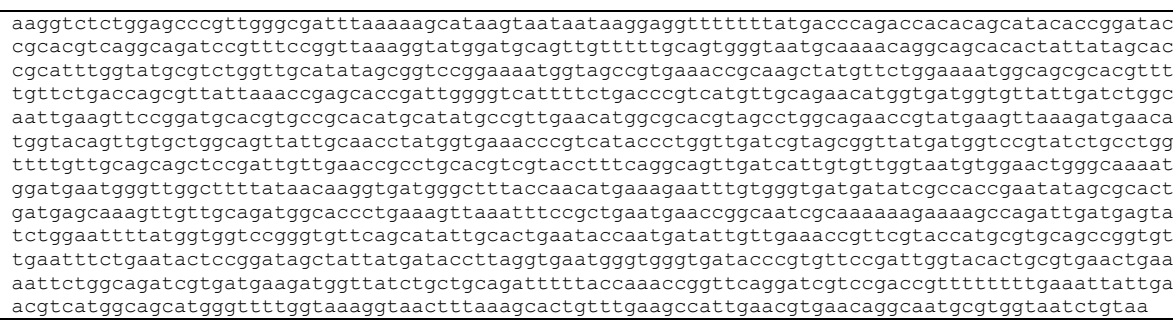 \\
\hline ECK120015440 & Terminator & tccggcaattaaaaaagcggctaaccacgccgctttttttacgtctgca \\
\hline $\mathrm{P}_{\text {Lteto-1 }}$ & Promoter & tccctatcagtgatagagattgacatccctatcagtgatagagatactgagcac \\
\hline RiboJ64 & Insulator & aggagtcaattaatgtgcttttaattctgatgagacggtgacgtcgaaactccctctacaaataattttgtttaa \\
\hline RBS-ScHmO & RBS & ccggcgacgtccgccgctgcaggcacacgtacttggctccagacaactcgaaacttacaataaggaggtatttt \\
\hline $\mathrm{ScHmO}$ & Gene & 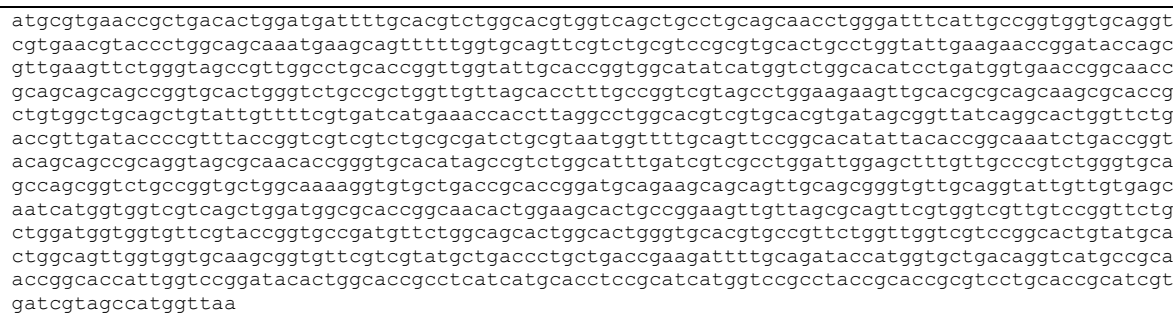 \\
\hline L3S2P24 & Terminator & ctcggtaccaaattccagaaaagacacccgaagggtgttttttcgttttggtcc \\
\hline PVancca & Promoter & attggatccaattgacagctagctcagtcctaggtaccattggatccaat \\
\hline SarJ & Insulator & gactgtcgccggatgtgtatccgacctgacgatggcccaaaagggccgaaacagtcctctacaaataattttgtttaa \\
\hline RBS-PpMdIC & RBS & ttcgcatccgagcccagataatagtatttagtacagtaaggaggtttttt \\
\hline PpMdiC & Gene & 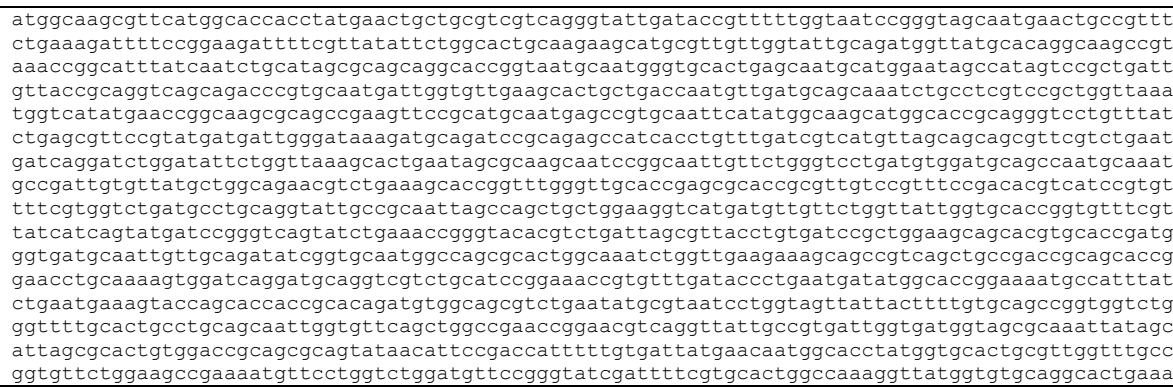 \\
\hline
\end{tabular}




\begin{tabular}{|c|c|c|}
\hline & & $\begin{array}{l}\text { gcagataatctggaacagctgaaaggtagcctgcaagaggcactgagcgcaaaaggtccggttctgattgaagttagcaccgttagtccggtg } \\
\text { aaataa }\end{array}$ \\
\hline ECK120010876 & Terminator & taaggttgaaaaataaaaacggcgctaaaaagcgccgttttttttgacggtggta \\
\hline $\mathrm{P}_{\mathrm{tac}}$ & Promoter & tgttgacaattaatcatcggctcgtataatgtgtggaattgtgagcgctcacaatt \\
\hline RiboJ51 & Insulator & agtagtcaccggctgtgcttgccggtctgatgagcctgtgaaggcgaaactacctctacaaataattttgtttaa \\
\hline RBS-AdwTA & RBS & aggtaacaattttcaatacaataaggaggtatttttt \\
\hline Ad $\omega T$ TA & Gene & 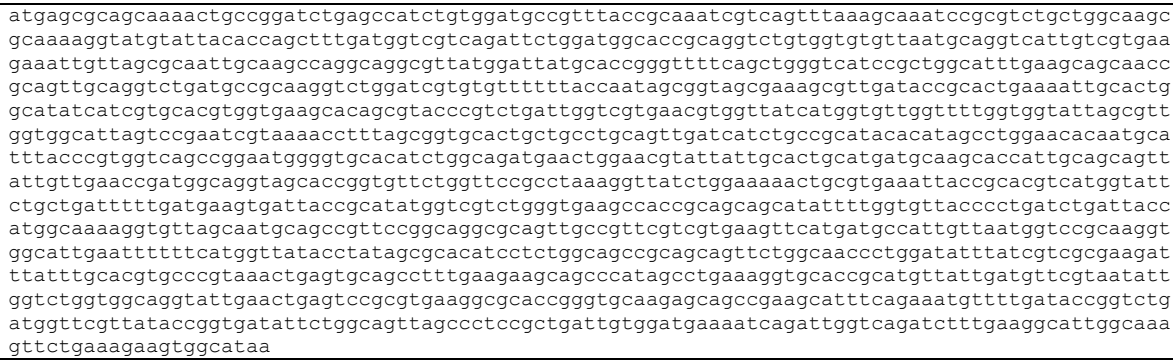 \\
\hline RBS-Pp1 $1 \omega T A$ & RBS & ttgtagacttacagccctagctgaaaaataattaggaggtcctat \\
\hline Pp1WTA & Gene & 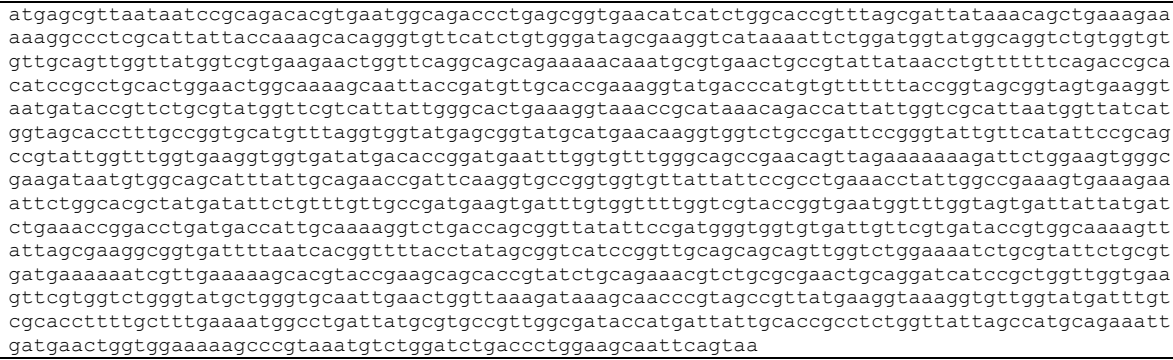 \\
\hline 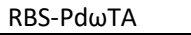 & RBS & cggcagccggggactactgagactcgaagatatacacaataaggaggtttttt \\
\hline Pd $\omega$ TA & Gene & 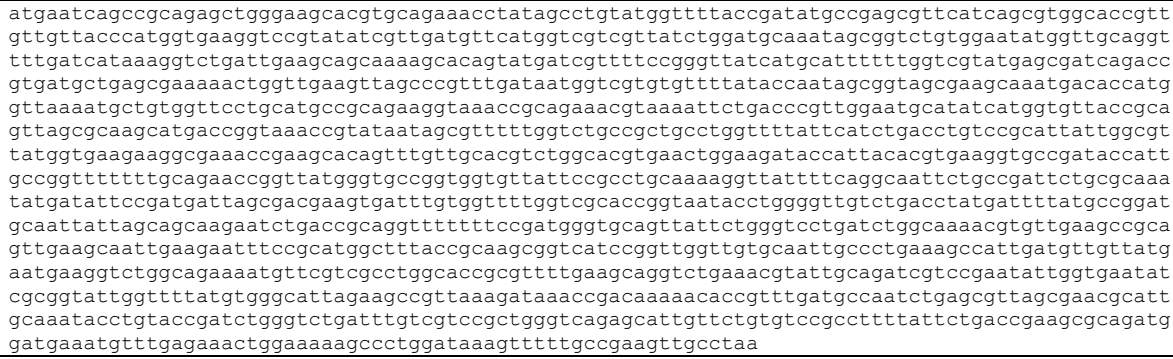 \\
\hline RBS-VfwTA & RBS & ggtacatcagtcctgtaggctaagccaacgtaaggagacaaagagtaaacggcgtagaataaactacgataaggaggtaattt \\
\hline VfWTA & Gene & 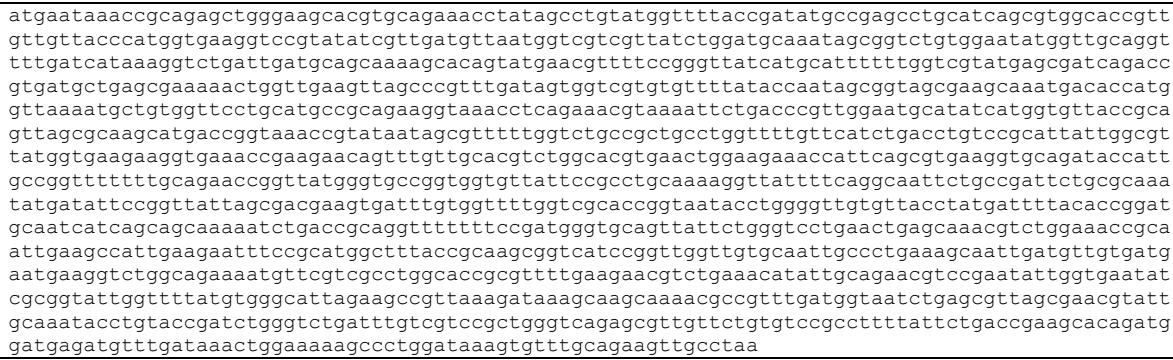 \\
\hline RBS-SpATA & RBS & gggctatccaggcatagaacgcttaacaaacctaaggagaattttt \\
\hline SpATA & Gene & 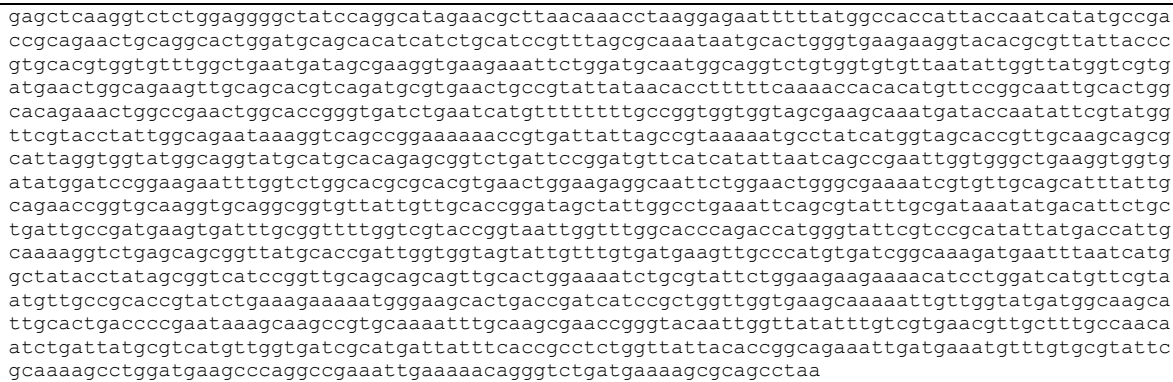 \\
\hline ECK120029600 & Terminator & ttgagaagagaaaagaaaaccgccgatcctgtccaccgcattactgcaaggtagtggacaagaccggcggtcttaagttttttggctgaa \\
\hline
\end{tabular}




\begin{tabular}{|c|c|c|}
\hline $\begin{array}{l}\text { pAC.157.ScHma } \\
\text { S.ScHmO.PpMd } \\
\text { IC.SpATA }\end{array}$ & Plasmid & 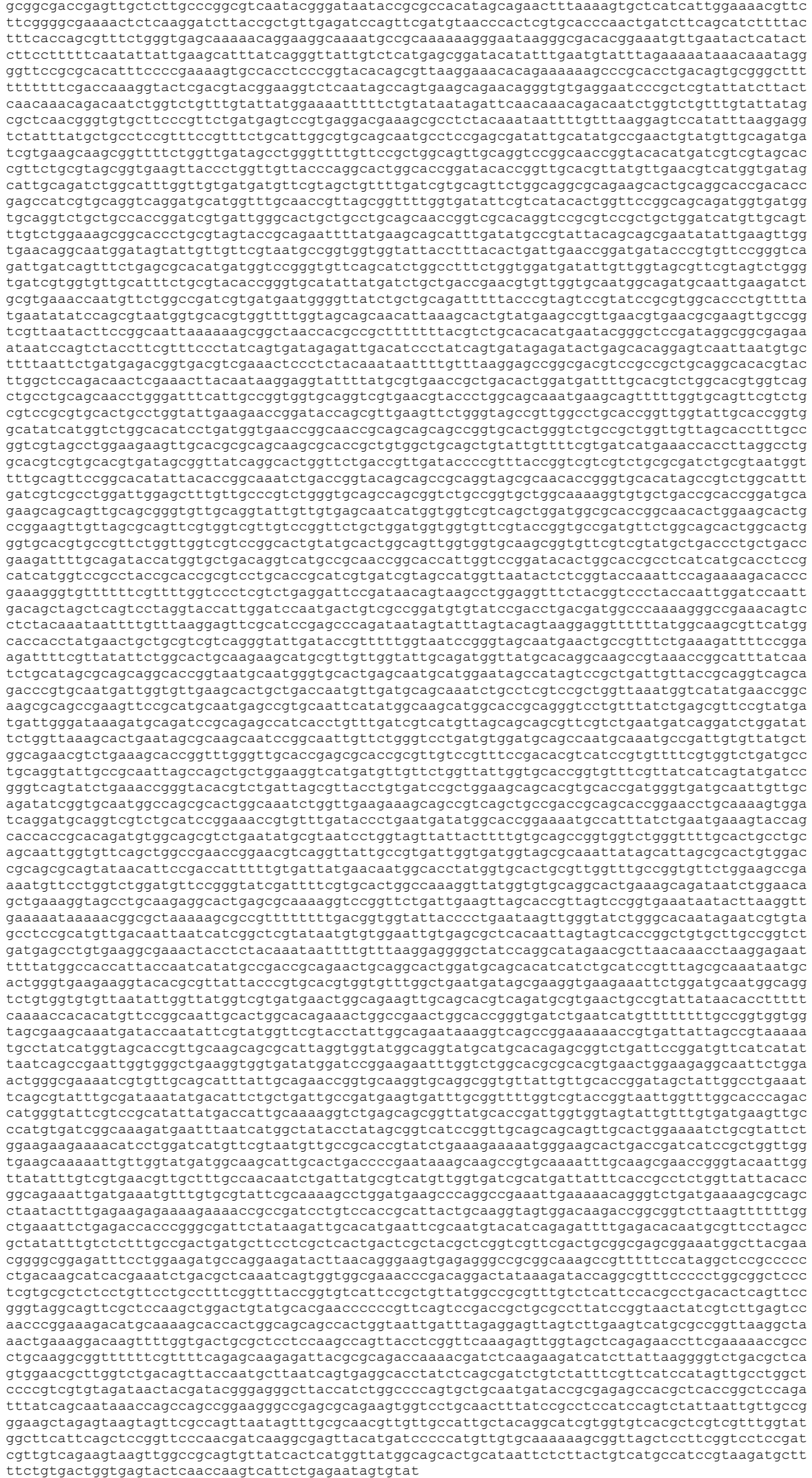 \\
\hline
\end{tabular}




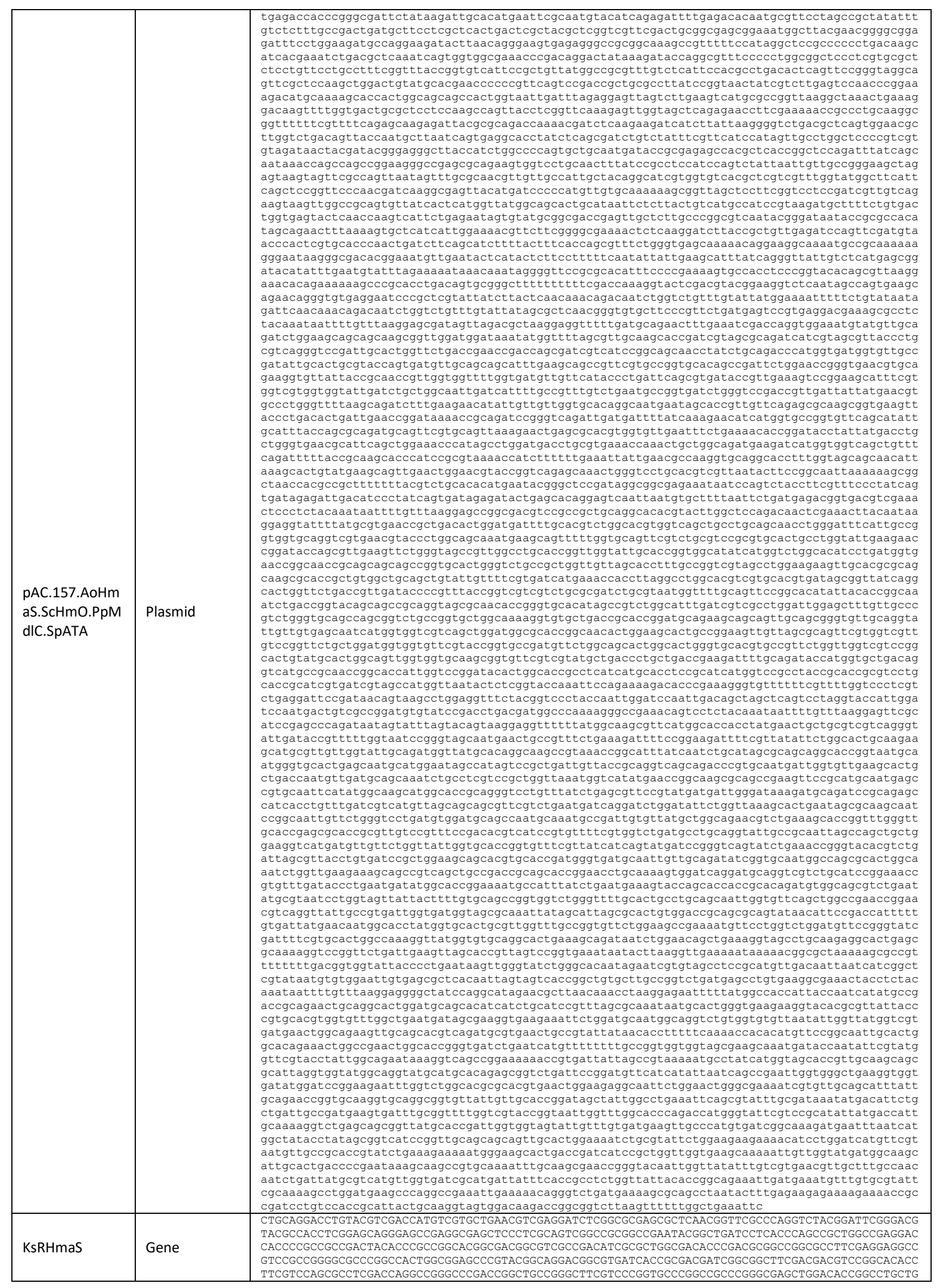




\begin{tabular}{|c|c|c|}
\hline & & 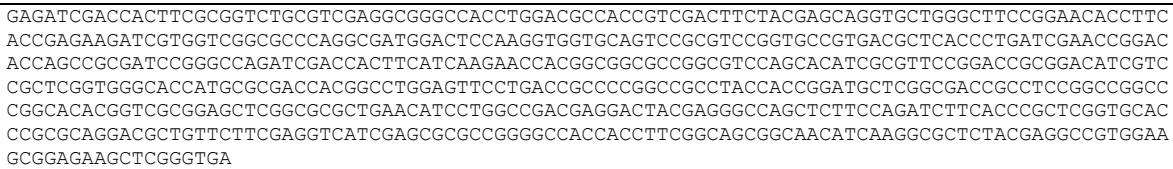 \\
\hline SsSHmaS & Gene & 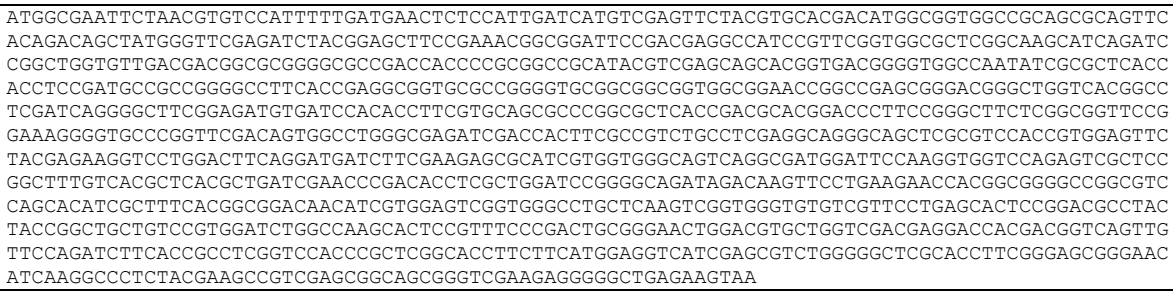 \\
\hline ThHmaS & Gene & 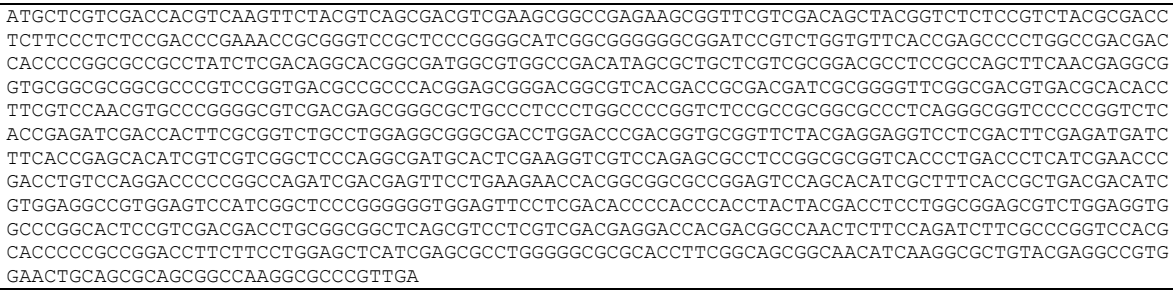 \\
\hline $\mathrm{SIHMaS}$ & Gene & 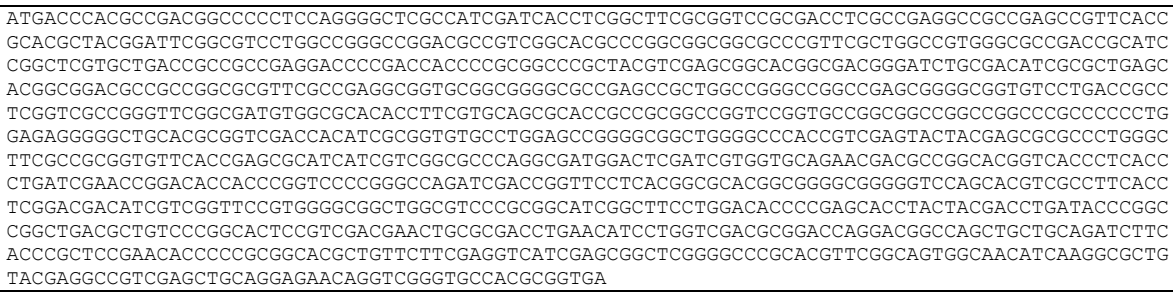 \\
\hline KsNHmaS & Gene & 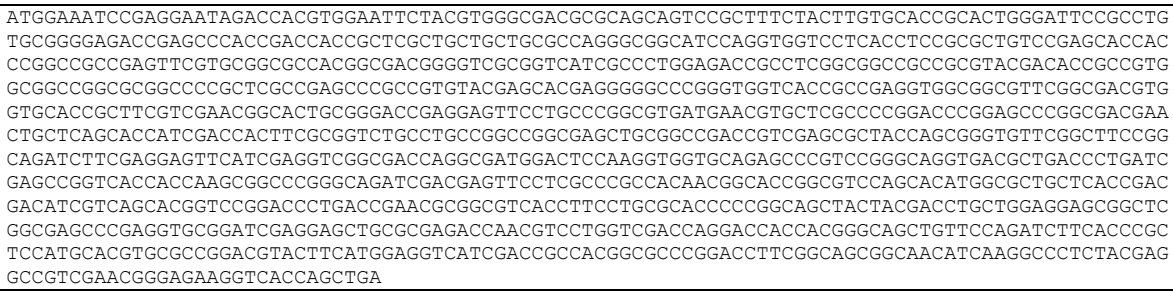 \\
\hline LaHmaS & Gene & 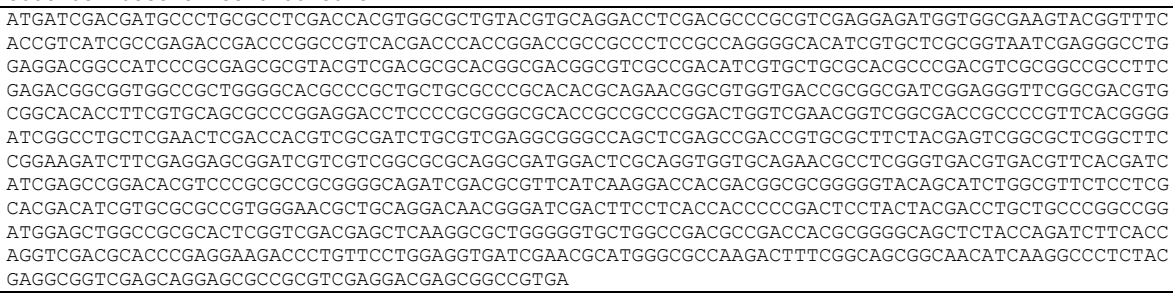 \\
\hline mGeHmaS & Gene & 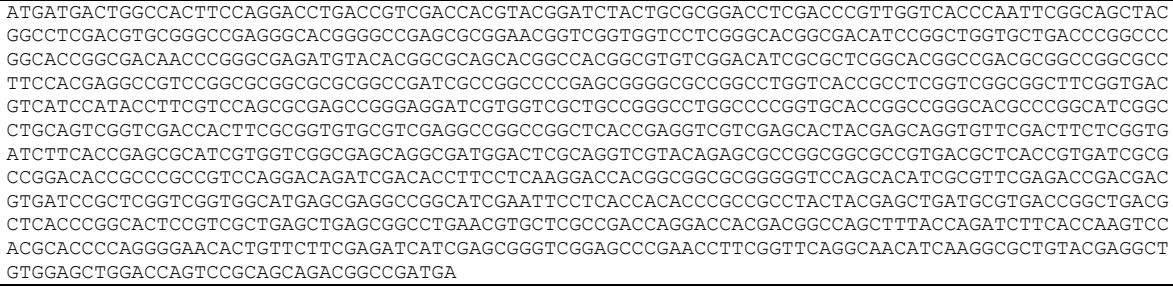 \\
\hline SsRHmaS & Gene & 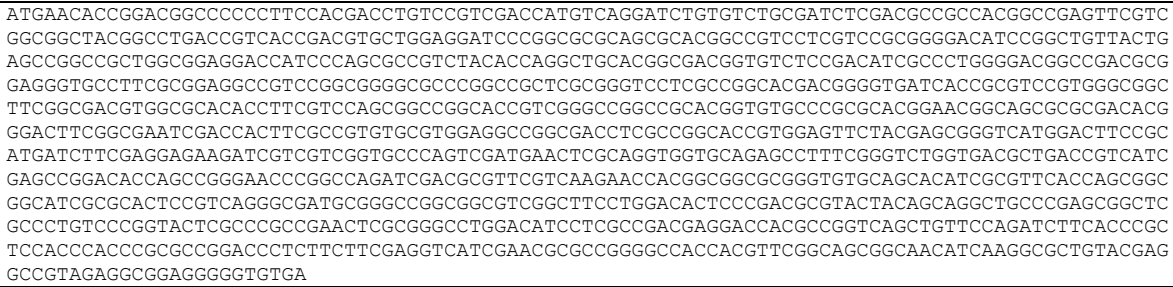 \\
\hline Ss1HmaS & Gene & $\begin{array}{l}\text { ATGACCTTCTCTCCCGCATTCGGCATCAGCCATGTCGAATTCCACGTCGCGACGTCGACTCGGCCGCGGCGAGCTGACCGACCGCTACGGC } \\
\text { "TCCGCCCGGGGCCCGCGCTCATCCGCGAGGCGACTCCCTCGCACTGCGCCAGGCCGCATCGTCCTCGTCTCACCCAGCACGCTCG } \\
\text { CCGCACCACCCGGGAGCGGCTACGTCTGGCGCACGGCGACGGCGTCGCCGACATCGCGCTGACCGTGGCCGACGTACCCGCGTCTTCGAC }\end{array}$ \\
\hline
\end{tabular}




\begin{tabular}{|c|c|c|}
\hline & & 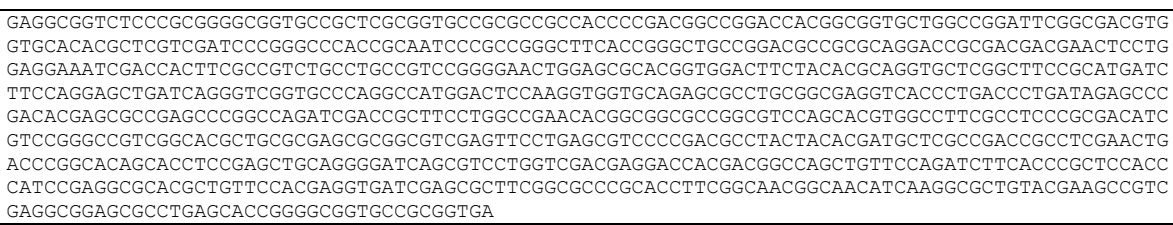 \\
\hline NsHmaS & Gene & 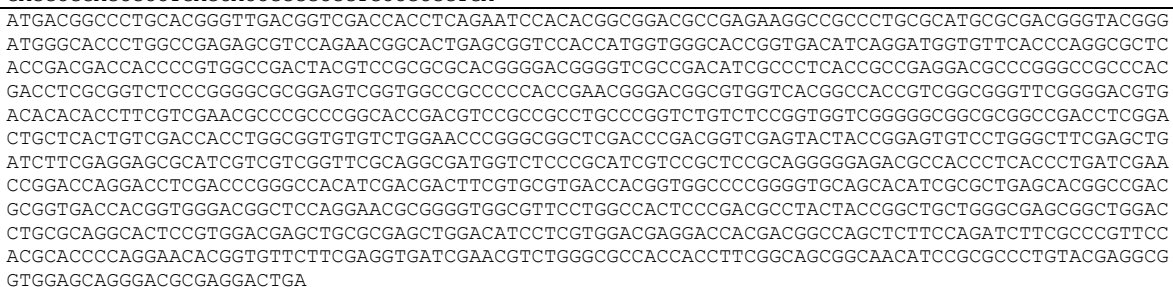 \\
\hline Ss $2 \mathrm{HmaS}$ & Gene & 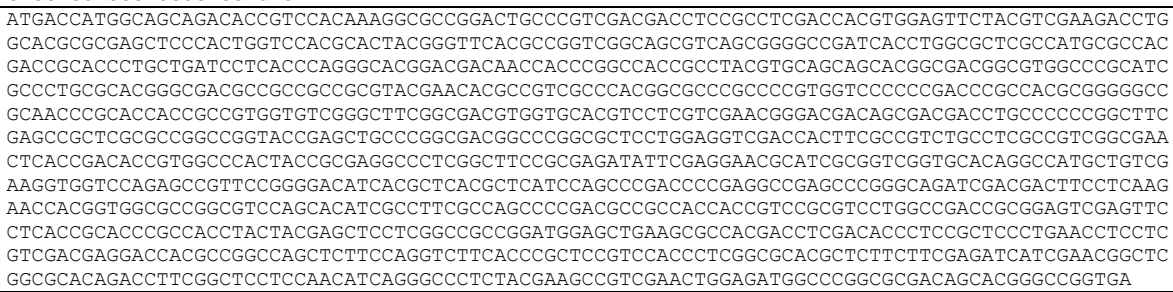 \\
\hline SsCHmaS & Gene & 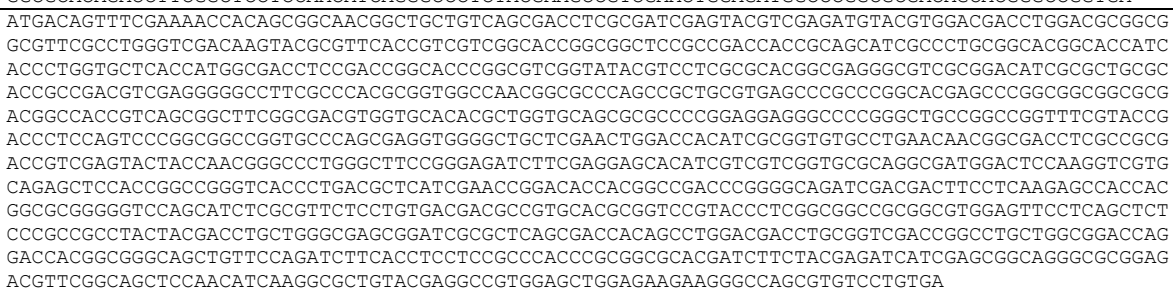 \\
\hline SaHmaS & Gene & 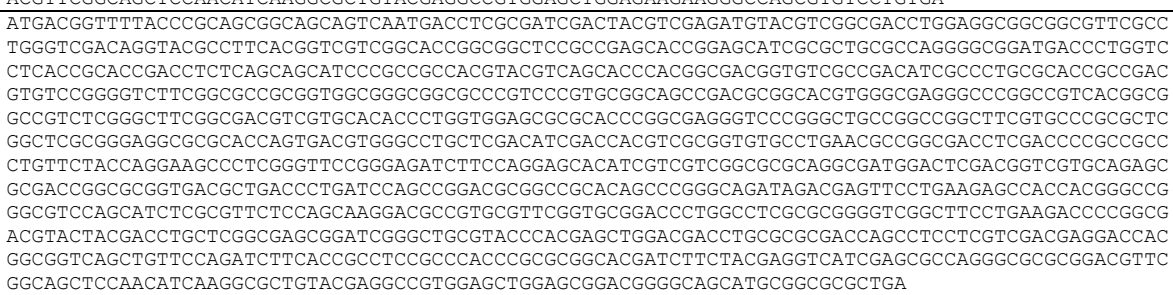 \\
\hline SsYHmaS & Gene & 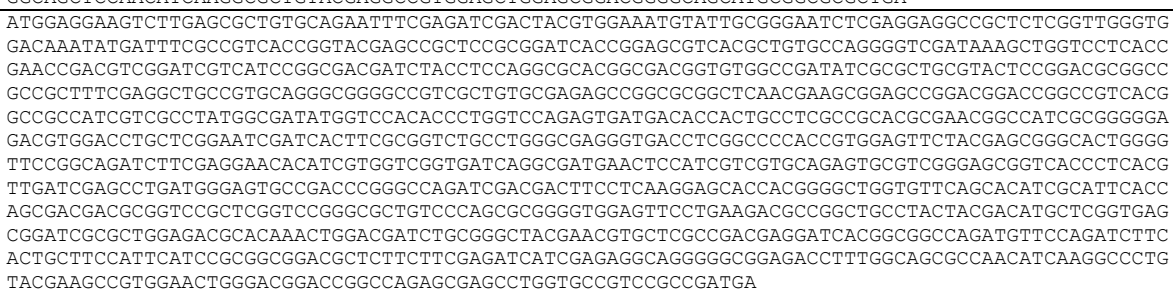 \\
\hline KaHmaS & Gene & 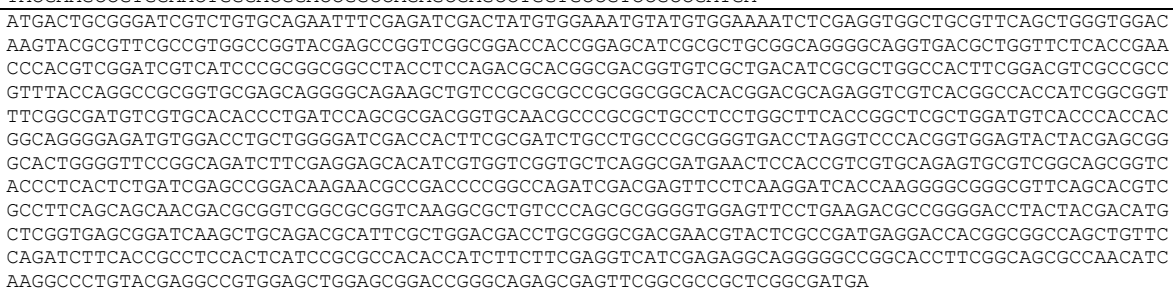 \\
\hline VEGHmaS & Gene & 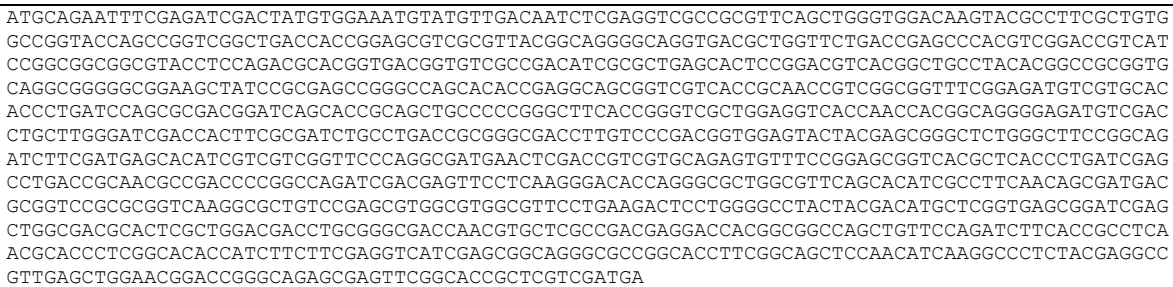 \\
\hline
\end{tabular}




\begin{tabular}{|c|c|c|}
\hline AsHmaS & Gene & 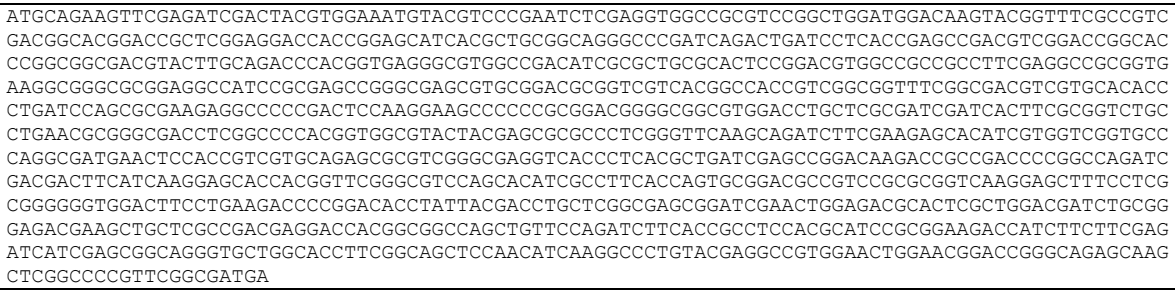 \\
\hline AtHmaS & Gene & 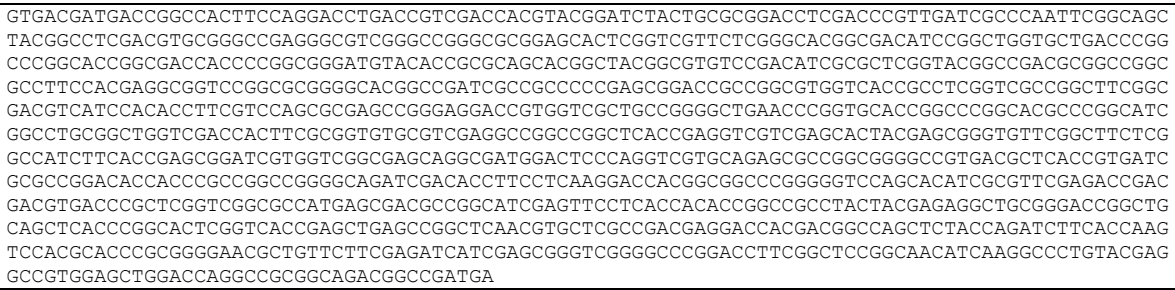 \\
\hline
\end{tabular}




\section{References}

1. Meyer, A. J., Segall-Shapiro, T. H., Glassey, E., Zhang, J., and Voigt, C. A. (2019) Escherichia coli "Marionette" strains with 12 highly optimized small-molecule sensors, Nat. Chem. Biol. 15, 196-204. 